\title{
Accurate Insulating Oil Breakdown Voltage Model Associated with Different Barrier Effects
}

\author{
Sherif S. M. Ghoneim ${ }^{1}{ }^{\mathbb{D}}$, Sobhy S. Dessouky ${ }^{2}$, Ahmed Boubakeur ${ }^{3} \mathbb{D}$, Adel A. Elfaraskoury ${ }^{4}$, \\ Ahmed B. Abou Sharaf ${ }^{5}$, Karar Mahmoud ${ }^{6,7}\left(\mathbb{D}\right.$, Matti Lehtonen ${ }^{6}$ (D) and Mohamed M. F. Darwish ${ }^{6,8, * \mathbb{D}}$
}

check for updates

Citation: Ghoneim, S.S.M.; Dessouky, S.S.; Boubakeur, A.; Elfaraskoury, A.A.; Abou Sharaf, A.B.; Mahmoud, K.; Lehtonen, M.; Darwish, M.M.F. Accurate Insulating Oil Breakdown Voltage Model Associated with Different Barrier Effects. Processes 2021, 9, 657. https://doi.org/ $10.3390 /$ pr9040657

Academic Editor: Kody Powell

Received: 7 March 2021

Accepted: 7 April 2021

Published: 9 April 2021

Publisher's Note: MDPI stays neutral with regard to jurisdictional claims in published maps and institutional affiliations.

Copyright: (c) 2021 by the authors. Licensee MDPI, Basel, Switzerland. This article is an open access article distributed under the terms and conditions of the Creative Commons Attribution (CC BY) license (https:// creativecommons.org/licenses/by/ $4.0 /)$
1 Department of Electrical Engineering, College of Engineering, Taif University, P.O. Box. 11099, Taif 21944, Saudi Arabia; s.ghoneim@tu.edu.sa

2 Electrical Engineering Department, Faculty of Engineering, Port Said University, Port Said 42526, Egypt; sobhyserry@eng.psu.edu.eg

3 Laboratoire de Recherche en Electrotechnique L.R.E, Ecole Nationale Polytechnique (ENP), BP 182, El-Harrach, Algiers 16200, Algeria; ahmed.boubakeur@g.enp.edu.dz

4 Extra High Voltage Research Centre, Egyptian Electricity Holding Company, Cairo 11517, Egypt; dr.elfaraskoury21@gmail.com

5 Mataria Technical College, Ministry of Higher Education, Cairo 11735, Egypt; ab.abosharaf@gmail.com

6 Department of Electrical Engineering and Automation, School of Electrical Engineering, Aalto University, FI-00076 Espoo, Finland; karar.mostafa@aalto.fi (K.M.); matti.lehtonen@aalto.fi (M.L.)

7 Department of Electrical Engineering, Faculty of Engineering, Aswan University, Aswan 81542, Egypt

8 Department of Electrical Engineering, Faculty of Engineering at Shoubra, Benha University, Cairo 11629, Egypt

* Correspondence: mohamed.m.darwish@aalto.fi or mohamed.darwish@feng.bu.edu.eg

Abstract: In modern power systems, power transformers are considered vital components that can ensure the grid's continuous operation. In this regard, studying the breakdown in the transformer becomes necessary, especially its insulating system. Hence, in this study, Box-Behnken design (BBD) was used to introduce a prediction model of the breakdown voltage $(V B D)$ for the transformer insulating oil in the presence of different barrier effects for point/plane gap arrangement with alternating current $(\mathrm{AC})$ voltage. Interestingly, the BBD reduces the required number of experiments and their costs to examine the barrier parameter effect on the existing insulating oil $V B D$. The investigated variables were the barrier location in the gap space $(a / d) \%$, the relative permittivity of the barrier materials $\left(\varepsilon_{r}\right)$, the hole radius in the barrier $(h r)$, the barrier thickness $(t h)$, and the barrier inclined angle $(\theta)$. Then, only 46 experiment runs are required to build the BBD model for the five barrier variables. The BBD prediction model was verified based on the statistical study and some other experiment runs. Results explained the influence of the inclined angle of the barrier and its thickness on the $V B D$. The obtained results indicated that the designed BBD model provides less than a $5 \%$ residual percentage between the measured and predicted $V B D$. The findings illustrated the high accuracy and robustness of the proposed insulating oil breakdown voltage predictive model linked with diverse barrier effects.

Keywords: transformers; breakdown voltage; barrier effect; Box-Behnken design

\section{Introduction}

A transformer is a crucial piece of equipment in the power system networks. The transformer's primary failure comes from the insulating system's deterioration, which consists of insulating oil and paper [1,2]. The transformer oil remains the most suitable liquid used in high-voltage apparatus as an insulating medium, but it still breaks under electrical and thermal stresses [3-8]. In the presence of a barrier in the insulating oil, the risk of the breakdown is reduced due to the stopping of the charge carriers by the barrier; then, these charge carriers accumulate on the barrier surface, constituting the barrier surface charge. Moreover, the barrier plays a significant role in impeding the discharge 
in the insulating oil of power transformers by encountering particle movement [9]. The breakdown voltage $(V B D)$ of homogeneous and non-homogeneous field gaps is affected mainly by inserting thin dielectric barriers in the gaps; this phenomenon is called the barrier effect. This effect is characterized by the electric field's uniformity between the barrier and the plane electrode, increasing the VBD. Thus, studying the influence of such barrier effect on the $V B D$ of the transformer oil is essential [10].

The barrier effect was observed first in 1920 by C.P. Steinmetz in the point/plane air gaps [11]. Some former studies have directed to investigate the consequence of the barrier set, e.g., the location of the barrier concerning the barrier diameter (D), the space of gap $(a / d) \%$, and the gap space among the electrodes $(\mathrm{d})$ under different applied voltages and gap space configurations [11-13]. The influence of surface conductivity of the barrier system on the VBD was presented in [14]. A rod/plane arrangement with the 80 $\mathrm{mm}$ distance between the high-voltage electrode (rod) and a grounded plane electrode was used. A single barrier was placed in the arrangement, and its surface resistivity was decreased systematically. A decrease in the $V B D$ arrangement with a reduction in surface resistivity was observed for positive, negative lightning impulse and alternating current (AC) voltage. The effect of barriers at early discharge and the failure stages for different field arrangements (homogenous and non-homogenous) was presented in [15]. The barrier location influences the failure stress, not the onset discharges. The effect of the barrier on the contaminated particle movements was investigated with the oil volume variation. The kraft paper's influence on preventing the bridging of the pressboard fiber particles in the insulating oil through experimental works was illustrated. Three different kraft pressboard paper types under different AC and DC voltages were examined in [16]. Recently, artificial intelligence and machine learning techniques have been employed in several applications with promising performance in power system applications with renewables [17-28]. Specifically, an artificial neural network (ANN) was presented in [29] to study the barrier effect parameters on the $V B D$ of the transformer insulating oil for the point/plane and plane/plane gaps under AC high voltage. The results showed the ANN model's capability to predict the $V B D$ with the barrier parameters' variation.

A mathematical and statistical model using the response surface methodology (RSM) includes some techniques such as the center composite face (CCF) and Box-Behnken design (BBD). They have been used to model and analyze the relationship between specific experiments' responses and their variable influence. In these techniques, a minimum number of experiment runs is required to reduce the experiment cost [30]. A second-order model was constructed using CCF and BBD in $[13,31]$ to inspect the influence of different barrier parameters, such as barrier place in the gap spacing, the gap spacing, and the barrier diameter of point/plane electrode arrangement under AC voltage. The conclusion was that the type of RSM technique affects the constructed model's accuracy and the cost of experimental works [31].

Previous works have studied the effect of some barrier variables on the strength of the insulating oil and its VBD, e.g., the barrier location and its diameter and the gap space between the electrodes $[3,9,12,13,31]$. In the current work, the effect of some new barrier variables is investigated. These variables are the barrier holes that may develop from the faults, whether intentional or accidental, and the barrier thickness, dielectric constant, and inclination angle. Moreover, mathematical modeling was used to construct a model linking the relation between the VBD and the barrier variables, such as a CCF design [13]. It shows a significant deviation in some cases between the measured and predicted $V B D$ (17.17\% deviation is a maximum). The proposed BBD technique was used to reduce this deviation. The number of experiments runs required for a given number of BBD factors is less than that for CCF. For five experiment factors, BBD requires 46 experiment runs, and CCF requires 52 experiment runs. In general, the greater number of variables in the model leads to many laboratory experiments. More efforts in the modeling process will be needed to create the model. All the previous reasons refer to the novelty of the current work. 
Investigating the influence of more than three variables and their interaction on a particular experiment response is complicated and requires many experiments. Therefore, reducing the number of experiments with variables of more than three is a great challenge. Therefore, BBD is a technique used to reduce the number of experiments and then reduce the experiment cost. The number of experiments to build the relationship between the response based on the experiment variables depends on the number of variables; that is, 15 experiment runs are required for three experimental variables, 27 runs for four experiment variables, and 46 experiment runs for five experiments variables.

In this study, new barrier variables are considered to investigate their effects on the $V B D$ of insulating oils with point / plane gap configuration under alternating current (AC) voltage based on BBD. These barrier variables are the barrier location in the gap space $(a / d) \%$, the dielectric constant of barrier material $\left(\varepsilon_{r}\right)$, the hole radius in the barrier $(h r)$, the barrier thickness $(t h)$, and the inclined angle of the barrier in the gap space $(\theta)$. The advantage of using the BBD technique in treating the difficulties of practical limits is avoiding risky mixtures because the sharp edges and star points are evaded [31]. Then, altogether points nominated to build the BBD model lie on the anticipated region (i.e., studied data region). The BBD declines the chosen number of experiment runs for the constructed model. A total of 46 experiment runs are required to simulate the relation between the $V B D$ as a response and five barrier variables. A prediction equation is developed based on BBD, and the significance of each term in this equation is investigated with the statistical study to obtain the approximated equation. The results of the predicted equation and its approximation provide minimum errors with 20 new experiment runs. In all cases, the errors are always less than $5 \%$.

\section{Experimental Works and Results}

\subsection{Experimental Setup}

The BBD model is built based on the experimental work results established in the Extra High-Voltage Research Center of the Egyptian Electricity Holding Company. The experiments are developed using a plexiglass tank with $25 \times 25 \times 35 \mathrm{~cm}$ filled with $18.75 \mathrm{~L}$ of insulating oil. A $100 \mathrm{kV}$ AC source is used with a capacitor divider for applying the AC high voltage on the point/plane gap configuration, as shown in Figure 1. Three types of barrier material are used (mica with a dielectric constant $\left(\varepsilon_{r}\right) 2.5$, pressboard with 3 , and acrylic with 3.5). The gap space is constant at $4 \mathrm{~cm}$, and the circular barrier diameter is fixed at $7 \mathrm{~cm}$ for all barriers. An earthed electrode is a plane with $17 \mathrm{~cm}$ in a diameter ring shape. The barrier is suspended in the gap space with the help of an acrylic bar. The transformer insulating oil kind is Diala D, where its dielectric strength is above $30 \mathrm{kV} / \mathrm{cm}$ (without treatment) as well as greater than $70 \mathrm{kV} / \mathrm{cm}$ (with treatment) based on both IEC 60296 and IEC $60156[32,33]$. The characteristics of the insulating oil shell Diala D are illustrated in Table 1. Note that the treatment of the original oil increases the breakdown voltage to more than $70 \mathrm{kV}$. Figure 2 explains the experimental arrangement of the point/plane gap configuration with the inclined barrier. The barrier location $((a / d) \%)$ is varied from $25 \%$ to $100 \%$ in the gap space $\mathrm{d}$. Different barrier materials are used with different dielectric constants that range from 2.5 to 3.5. The hole radius $(h r)$ made in the barrier varies with values of $0.75,1.25$, and $1.75 \mathrm{~mm}$. The holes were also made in the center of the barrier. The thickness $(t h)$ of the barrier also varies between 2 and $4 \mathrm{~mm}$. The inclined angle of the barrier is considered $0^{\circ}, 45^{\circ}$, and $90^{\circ}$. The barrier is in a horizontal position at $0^{\circ}$, and it is in a vertical one for $90^{\circ}$. Based on the IEC 60156, the average value of six sequences runs on the insulating oil is considered. Then, each value of breakdown voltage is the average value of the applied voltage's six consecutive runs. 


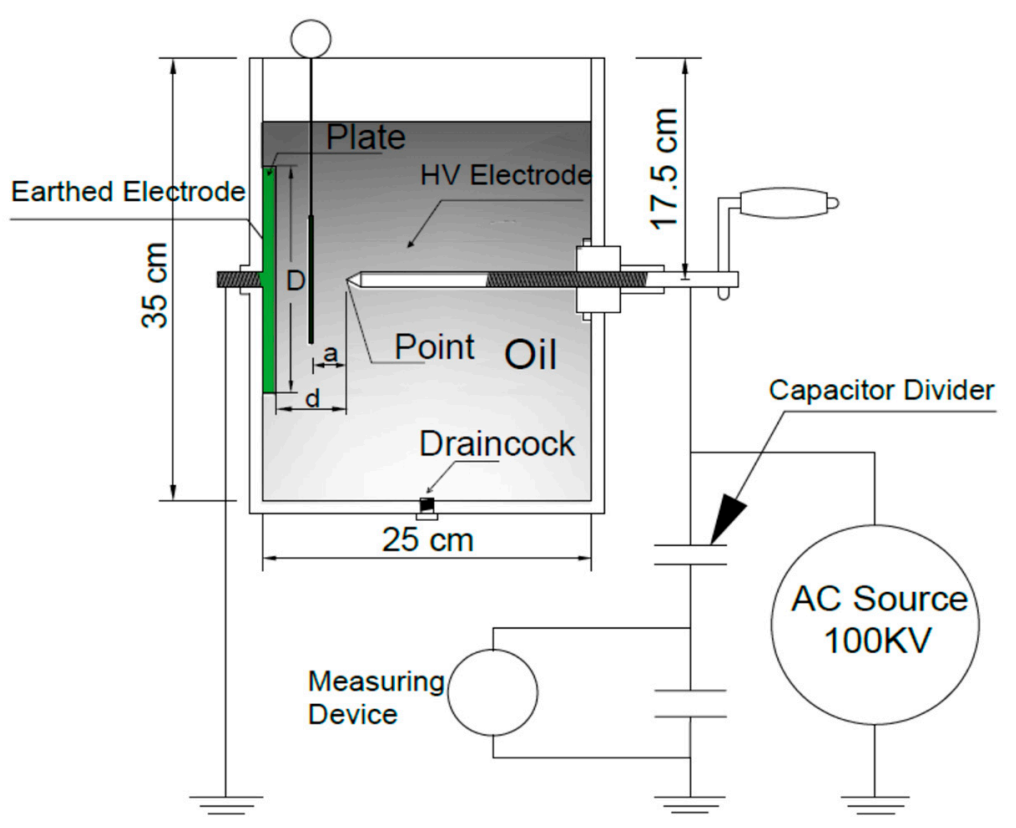

Figure 1. Schematic of the oil tank with point/plane gap configuration.

Table 1. Characteristics of insulating oil shell Diala D.

\begin{tabular}{cccc}
\hline Item & Unit & IEC 60296 Requirements & Diala D \\
\hline $\begin{array}{c}\text { Density at } 20{ }^{\circ} \mathrm{C} \\
\text { Kinematic viscosity at } 2{ }^{\circ} \mathrm{C}\end{array}$ & $\mathrm{K} \mathrm{g} / \mathrm{m}^{3}$ & $<895$ & 877 \\
Breakdown voltage & $\mathrm{mm}^{2} / \mathrm{s}$ & - & 16.6 \\
$\quad$ after treatment) & $\mathrm{kV}$ & Min $70 \mathrm{kV}$ & $>30$ ( $>70$ upon treatment $)$ \\
$\begin{array}{c}\text { Water content } \\
\text { Dielectric dissipation factor at } 90^{\circ} \mathrm{C}\end{array}$ & - & 0.005 max (after treatment) & 0.0005 \\
Oxidation Stability $\left(164 \mathrm{~h} / 120^{\circ} \mathrm{C}\right)$ & $\mathrm{ppm}$ & - & $<40 \mathrm{drams} / \mathrm{IBC},<30 \mathrm{bulk}$ \\
Total acidity & $\mathrm{mg} \mathrm{KOH} / \mathrm{g}$ & Max. 0.3 & 0.26 \\
\hline
\end{tabular}

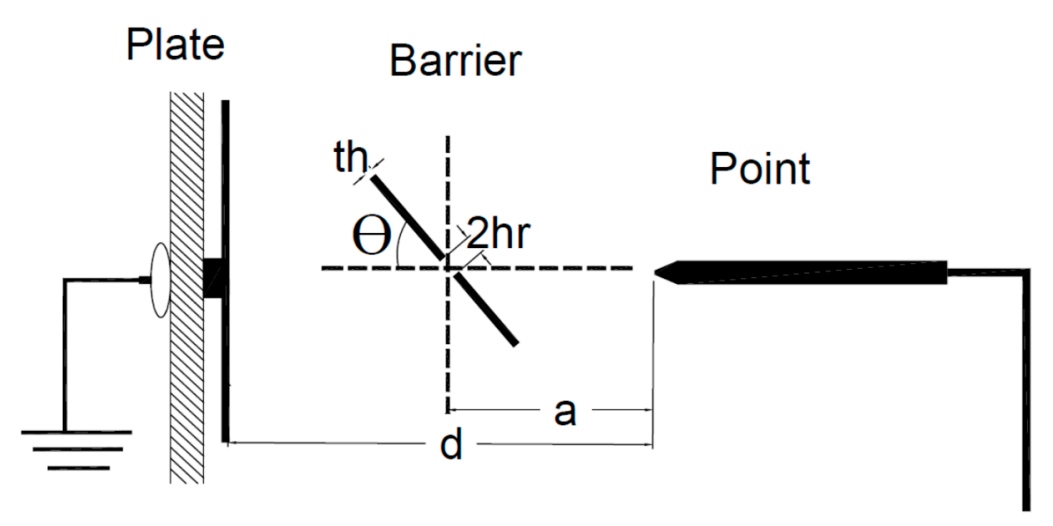

HV

Figure 2. Arrangement of point/plane gap with an inclined barrier.

\subsection{Results for Barrier Location (a/d)\% and Barrier Material $\left(\varepsilon_{r}\right)$}

The first barrier variable that influences the $V B D$ is the location of the barrier in the gap space. The variation in the $V B D$ with $(a / d) \%$ is illustrated in Figure 3 , where the $V B D$ is recorded when the barrier location varies from 25 to $100 \%$ of the gap space, and three types of barrier material are used with different dielectric constants. The maximum breakdown voltage occurs when the barrier is closing to the high voltage electrode. The breakdown 
voltage diminishes when the barrier is approaching the grounded electrode. When we construct the mathematical model, it is not convenient to put the variable $(a / d) \%$ equal to zero since $(a / d) \%$ minimum value is considered $25 \%$. Figure 3 illustrated the experiments investigating the effect of barrier location were conducted at $t h=2 \mathrm{~mm}$, without a hole, and with a vertical barrier position. Figure 3 demonstrates that the $V B D$ decreases with the increase in the $(a / d) \%$. When the $(a / d) \%$ is $100 \%$, the barrier's effect is reduced, and the $V B D$ reaches the gap's $V B D$ value without barrier. Moreover, the $V B D$ increases with a high dielectric constant as in acrylic.

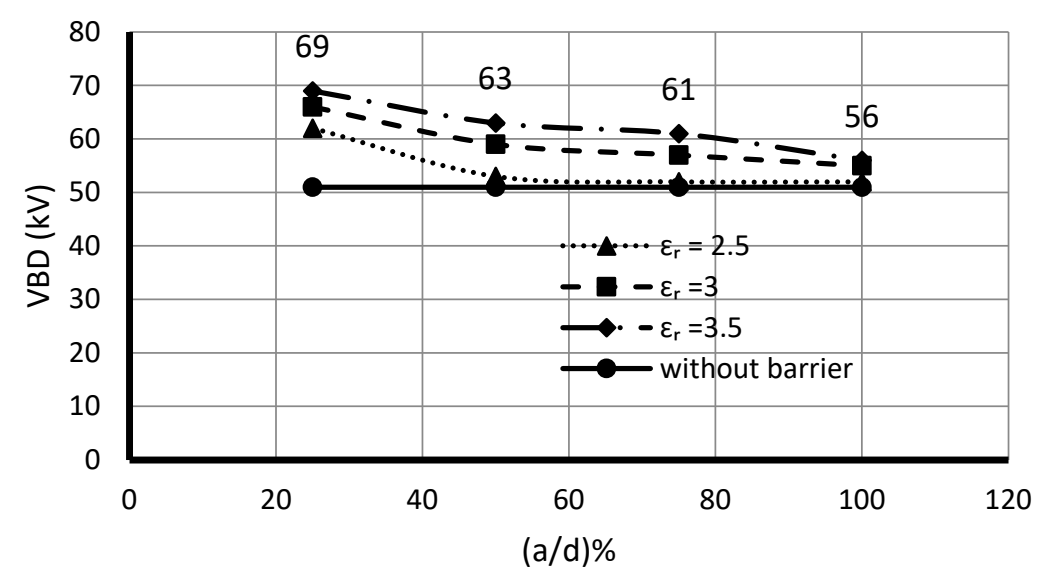

Figure 3. Effect of the barrier location on the breakdown voltage at different barrier materials.

\subsection{Results for Barrier Thickness (th)}

Figure 4 depicts the barrier thickness's impact on the insulating oil $V B D$ at diverse barrier locations in the gap space. The experiments' parameters are acrylic material, without a hole in the barrier, and vertical barrier position $\left(\theta=90^{\circ}\right)$. An increase in the barrier thickness results in an increase in the $V B D$ at a similar barrier position in the gap space.

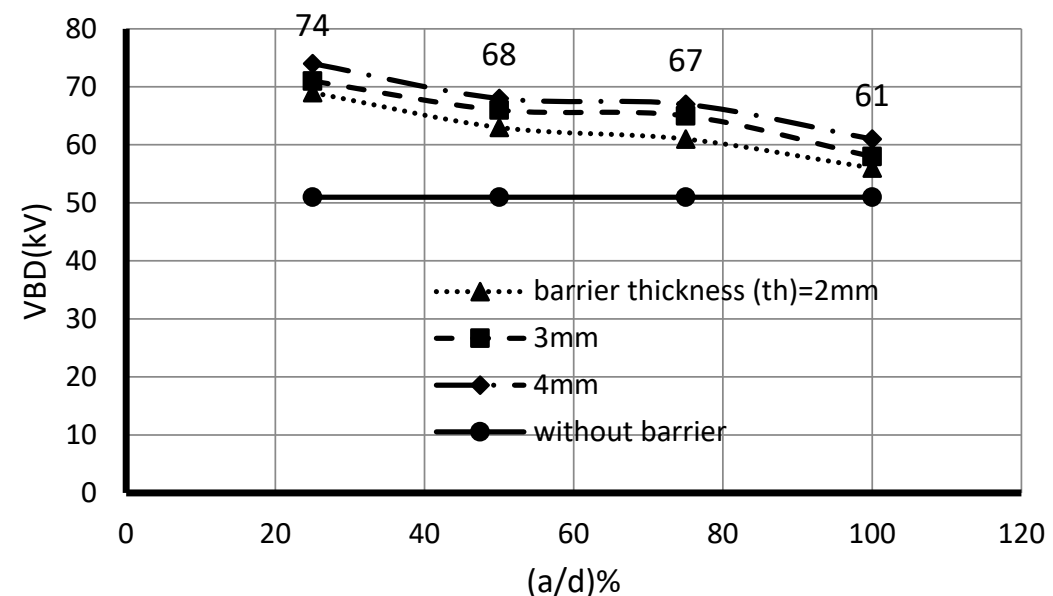

Figure 4. Effect of the barrier thickness on the breakdown voltage.

\subsection{Results for Barrier Hole Radius (hr)}

Figure 5 shows that the barrier without any hole significantly affects VBD. With a hole in the barrier, the $V B D$ of the point/plane oil gap decreases. In such a case, the barrier has a negative effect. Meanwhile, an increase in the hole radius leads to a reduction in the $V B D$ at the exact barrier location. When $(a / d) \%$ is $100 \%$, the barrier does not affect, and the $V B D$ reaches one of the gaps without the barrier. The experiments are conducted at the barrier thickness th equal to $2 \mathrm{~mm}$, acrylic barrier material, and the inclined angle $(\theta)$ equivalent to $90^{\circ}$. 


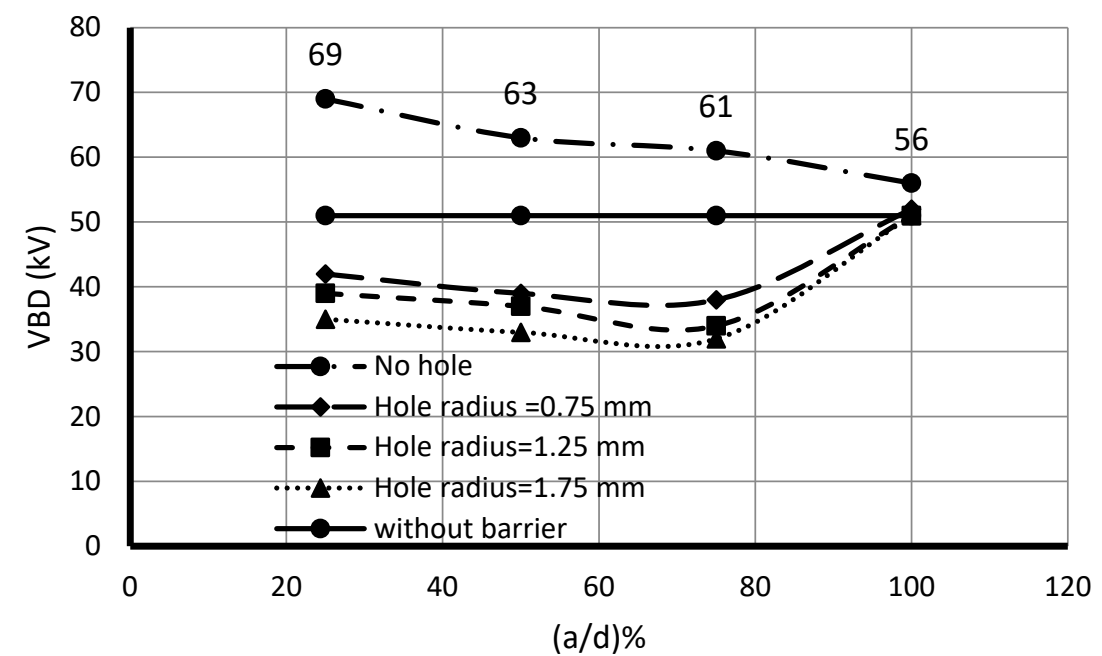

Figure 5. Effect of barrier hole radius on the breakdown voltage.

\subsection{Results for Barrier Inclined Angle $(\theta)$}

Figure 6 explains the relation between the $V B D$ and the barrier inclined angle $(\theta)$. The vertical position $\left(\theta=90^{\circ}\right)$ of the barrier plays an imperative role in increasing the $V B D$ of the power transformer insulating oil rather than any other inclined barrier angle or the barrier with a horizontal position. A decrease in $V B D$ is observed when the location of the barrier increases until $(a / d)$ reaches $100 \%$. Then, the effect of the barrier decreases, and the $V B D$ becomes close to that of the gap without barrier. The experiments' parameters are an acrylic barrier made of acrylic, without a hole in the barrier, and the barrier thickness (th) of $2 \mathrm{~mm}$.

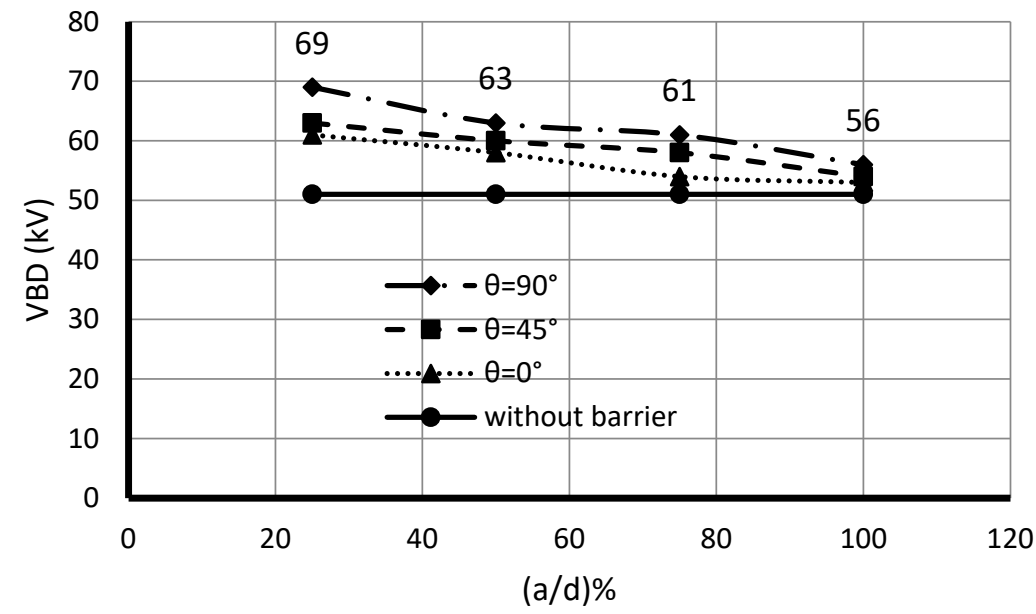

Figure 6. Effect of barrier inclined angle $(\theta)$ on the breakdown voltage.

The experimental results indicated that the breakdown voltage values were of low values because there is no physical mechanism consideration. It is unclear if they can be applied to other fluids.

\section{Box-Behnken Design (BBD)}

The design of experiments (DOE) is considered a feature of the RSM and has numerous practices. The CCF and BBD are considered the most known DOE methods [34]. $\mathrm{BBD}$ is recently viewed in many applications to investigate the effect of the experimental parameters on these experiments' responses, as in [13,31,35-40]. Further, it is lying on the division of applied statistics for analyzing, planning, and interpreting the controlled test for determining the parameters that regulate the reaction of practical experiments. Before 
conducting the investigation, two concepts must be considered: the experiment domain and the experiments' mathematical model [13]. The quadratic formula of the BBD model of the designed experiment is given by Equation (1) [41]:

$$
Y=\alpha_{0}+\sum_{i=1}^{N v} \alpha_{i} X_{i}+\sum_{i=1}^{N v} \sum_{j=1}^{N v} \alpha_{i j} X_{i} X_{j}+\sum_{i=1}^{N v} \alpha_{i i} X_{i}^{2}+\varepsilon
$$

where $\mathrm{Y}$ is the response, and $\mathrm{X}_{\mathrm{i}}$ refers to the input variables that influence the experiment response. $X_{i} X_{j}$ is the two-way (interaction) terms; the number is calculated as $k(k-1) / 2$, where $\mathrm{k}$ is the number of input variables. The $\mathrm{X}_{\mathrm{i}}{ }^{2}$ refers to the second-order of the variables. $\left(\alpha_{0}, \alpha_{\mathrm{ij}}, \alpha_{\mathrm{ii}}\right)$ is the coefficient of all terms in the quadratic equation. The $\varepsilon$ expresses the error of the equation, and $N_{v}$ is the number of experiment variables.

In the BBD, the input parameters (i.e., considered factors) are categorized into three different levels for each factor. These levels involve the minimum, mean, and maximum variable values. Note that the three levels are coded by $-1,0$, and 1 , respectively. For example, the barrier thickness variable th is regarded as 2,3 , and $4 \mathrm{~mm}$, which correspond to the coded values of $-1,0$, and 1 , respectively. The coding of other variables is explained in the study, as in Table 2. The coded value of the five barrier variables is described in Table 2.

Table 2. Coded and actual values of the input parameters of the barrier.

\begin{tabular}{cccc}
\hline \multirow{2}{*}{ Input Variables } & \multicolumn{3}{c}{ Coded Value } \\
\cline { 2 - 4 } & Minimum (-1) & Mean (0) & Maximum (1) \\
\hline$(a / d) \%$ & 25 & 50 & 75 \\
$\varepsilon_{r}(f / m)$ & 2.5 & 3 & 3.5 \\
$h r(m m)$ & 0.75 & 1.25 & 1.75 \\
$t h(m m)$ & 2 & 3 & 4 \\
$\theta$ & $0^{\circ}$ & $45^{\circ}$ & $90^{\circ}$ \\
\hline
\end{tabular}

BBD is considered a rotatable or nearly rotatable second-order design that needs three levels of each variable that influence a specific experiment response. It is recently widely used in many applications of the research environment [35-40]. These experiment variable levels are categorized into minimum, mean, and maximum levels, and they are coded as $-1,0$, and 1 , respectively. The required number of experiments runs $\left(N_{r}\right)$ for BBD design is determined as follows [42]:

$$
N_{r}=2 N_{v}\left(N_{v}-1\right)+C P_{0}
$$

$N_{v}$ represents the counting number of factors (i.e., input parameters), and $C P_{0}$ refers to the number of repetitions tests at the center point. Note that the coded values of the input variables of the experimental are clarified in Table 2.

The authors of [42] presented only the fundamentals, advantages, and limitations of the BBD for the optimization of analytical methods. They showed an example for three parameters only with 15 experiments runs where $C P_{0}$ is three. A total of 46 experiment runs are required according to Equation (2) with six points in the center values of the five variables to apply the BBD to the designed experiments to investigate the effect of five variables on the response of these experiments $(V B D)$. Table 3 illustrates the coded values, the values of the variables, and the response of the 46 experiments. A total of six points are repeated at the zero code of the variables to provide a $\mathrm{CP}_{0}-1$ degree of freedom for determining the experiment errors and enhancing the response's precision at these zero codes of the variables [43]. A total of 46 experiment runs are conducted to investigate the effect of the previous barrier variables on the VBD, as the BBD technique's requirement is illustrated in Table 3. Each experiment run is performed to satisfy the particular need of BBD. The first experiment run in Table 3 indicates that the $V B D$ is measured at the following conditions: the barrier location is minimum at $25 \%$ of the gap space, the dielectric strength $\left(\varepsilon_{r}\right)$ is minimum at 2.5 for mica barrier material, the radius of the hole in the barrier is at the 
mean value of $1.25 \mathrm{~mm}$, the barrier thickness is at $3 \mathrm{~mm}$ as a mean value of the thickness variable, and the inclined angle of the barrier is at a mean value of $45^{\circ}$. The remaining 46 experiment runs are conducted as illustrated in Table 3.

Table 3. Coded and actual numbers for five Box-Behnken design (BBD) input parameters.

\begin{tabular}{|c|c|c|c|c|c|c|c|c|c|c|c|}
\hline & \multirow[b]{2}{*}{$(a / d) \%$} & \multicolumn{3}{|c|}{ Coded Variables } & \multicolumn{7}{|c|}{ Actual Variables } \\
\hline & & $\varepsilon_{r}$ & $h r$ & th & $\theta$ & $(a / d) \%$ & $\varepsilon_{r}$ & $h r(m m)$ & th $(\mathrm{mm})$ & $\theta\left({ }^{\circ}\right)$ & $V B D(k V)$ \\
\hline 1 & -1 & -1 & 0 & 0 & 0 & 25 & 2.5 & 1.25 & 3 & 45 & 38 \\
\hline 2 & -1 & 1 & 0 & 0 & 0 & 25 & 3.5 & 1.25 & 3 & 45 & 42 \\
\hline 3 & 1 & -1 & 0 & 0 & 0 & 75 & 2.5 & 1.25 & 3 & 45 & 33 \\
\hline 4 & 1 & 1 & 0 & 0 & 0 & 75 & 3.5 & 1.25 & 3 & 45 & 38 \\
\hline 5 & 0 & 0 & -1 & -1 & 0 & 50 & 3 & 0.75 & 2 & 45 & 36 \\
\hline 6 & 0 & 0 & -1 & 1 & 0 & 50 & 3 & 0.75 & 4 & 45 & 43 \\
\hline 7 & 0 & 0 & 1 & -1 & 0 & 50 & 3 & 1.75 & 2 & 45 & 34 \\
\hline 8 & 0 & 0 & 1 & 1 & 0 & 50 & 3 & 1.75 & 4 & 45 & 41 \\
\hline 9 & 0 & -1 & 0 & 0 & -1 & 50 & 2.5 & 1.25 & 3 & 0 & 54 \\
\hline 10 & 0 & -1 & 0 & 0 & 1 & 50 & 2.5 & 1.25 & 3 & 90 & 38 \\
\hline 11 & 0 & 1 & 0 & 0 & -1 & 50 & 3.5 & 1.25 & 3 & 0 & 58 \\
\hline 12 & 0 & 1 & 0 & 0 & 1 & 50 & 3.5 & 1.25 & 3 & 90 & 41 \\
\hline 13 & -1 & 0 & -1 & 0 & 0 & 25 & 3 & 0.75 & 3 & 45 & 41 \\
\hline 14 & -1 & 0 & 1 & 0 & 0 & 25 & 3 & 1.75 & 3 & 45 & 39 \\
\hline 15 & 1 & 0 & -1 & 0 & 0 & 75 & 3 & 0.75 & 3 & 45 & 36 \\
\hline 16 & 1 & 0 & 1 & 0 & 0 & 75 & 3 & 1.75 & 3 & 45 & 36 \\
\hline 17 & 0 & 0 & 0 & -1 & -1 & 50 & 3 & 1.25 & 2 & 0 & 57 \\
\hline 18 & 0 & 0 & 0 & -1 & 1 & 50 & 3 & 1.25 & 2 & 90 & 36 \\
\hline 19 & 0 & 0 & 0 & 1 & -1 & 50 & 3 & 1.25 & 4 & 0 & 57 \\
\hline 20 & 0 & 0 & 0 & 1 & 1 & 50 & 3 & 1.25 & 4 & 90 & 43 \\
\hline 21 & 0 & -1 & -1 & 0 & 0 & 50 & 2.5 & 0.75 & 3 & 45 & 37 \\
\hline 22 & 0 & -1 & 1 & 0 & 0 & 50 & 2.5 & 1.75 & 3 & 45 & 36 \\
\hline 23 & 0 & 1 & -1 & 0 & 0 & 50 & 3.5 & 0.75 & 3 & 45 & 41 \\
\hline 24 & 0 & 1 & 1 & 0 & 0 & 50 & 3.5 & 1.75 & 3 & 45 & 39 \\
\hline 25 & -1 & 0 & 0 & -1 & 0 & 25 & 3 & 1.25 & 2 & 45 & 37 \\
\hline 26 & -1 & 0 & 0 & 1 & 0 & 25 & 3 & 1.25 & 4 & 45 & 44 \\
\hline 27 & 1 & 0 & 0 & -1 & 0 & 75 & 3 & 1.25 & 2 & 45 & 34 \\
\hline 28 & 1 & 0 & 0 & 1 & 0 & 75 & 3 & 1.25 & 4 & 45 & 40 \\
\hline 29 & 0 & 0 & -1 & 0 & -1 & 50 & 3 & 0.75 & 3 & 0 & 56 \\
\hline 30 & 0 & 0 & -1 & 0 & 1 & 50 & 3 & 0.75 & 3 & 90 & 39 \\
\hline 31 & 0 & 0 & 1 & 0 & -1 & 50 & 3 & 1.75 & 3 & 0 & 56 \\
\hline 32 & 0 & 0 & 1 & 0 & 1 & 50 & 3 & 1.75 & 3 & 90 & 38 \\
\hline 33 & -1 & 0 & 0 & 0 & -1 & 25 & 3 & 1.25 & 3 & 0 & 59 \\
\hline 34 & -1 & 0 & 0 & 0 & 1 & 25 & 3 & 1.25 & 3 & 90 & 41 \\
\hline 35 & 1 & 0 & 0 & 0 & -1 & 75 & 3 & 1.25 & 3 & 0 & 54 \\
\hline 36 & 1 & 0 & 0 & 0 & 1 & 75 & 3 & 1.25 & 3 & 90 & 35 \\
\hline 37 & 0 & -1 & 0 & -1 & 0 & 50 & 2.5 & 1.25 & 2 & 45 & 33 \\
\hline 38 & 0 & -1 & 0 & 1 & 0 & 50 & 2.5 & 1.25 & 4 & 45 & 40 \\
\hline 39 & 0 & 1 & 0 & -1 & 0 & 50 & 3.5 & 1.25 & 2 & 45 & 37 \\
\hline 40 & 0 & 1 & 0 & 1 & 0 & 50 & 3.5 & 1.25 & 4 & 45 & 44 \\
\hline 41 & 0 & 0 & 0 & 0 & 0 & 50 & 3 & 1.25 & 3 & 45 & 39 \\
\hline 42 & 0 & 0 & 0 & 0 & 0 & 50 & 3 & 1.25 & 3 & 45 & 38.5 \\
\hline 43 & 0 & 0 & 0 & 0 & 0 & 50 & 3 & 1.25 & 3 & 45 & 38 \\
\hline 44 & 0 & 0 & 0 & 0 & 0 & 50 & 3 & 1.25 & 3 & 45 & 38.5 \\
\hline 45 & 0 & 0 & 0 & 0 & 0 & 50 & 3 & 1.25 & 3 & 45 & 39 \\
\hline 46 & 0 & 0 & 0 & 0 & 0 & 50 & 3 & 1.25 & 3 & 45 & 39.5 \\
\hline
\end{tabular}

Equation (1) is used to build the BBD model for determining the relation between the experiment input variables and the response of the designed experiments. The number of coefficients $\left(N_{c}\right)$ of Equation (1) can be computed as follows:

$$
N_{c}=\left(N_{v}+1\right)\left(N_{v}+2\right) / 2
$$


$N_{c}$ is the number of coefficients $\left(\alpha_{0}, \alpha_{\mathrm{i}}, \alpha_{\mathrm{ij}}\right.$, and $\left.\alpha_{\mathrm{ii}}\right)$, and $N_{v}$ is the number of experiment variables. From Equation (3), 21 coefficients of Equation (1) are developed.

The Matlab software calculates Equation (1) coefficients, while the equivalent BBD model of the predicted formula of $V B D$ can be explained as in Equation (4).

$$
\begin{aligned}
V B D & =38.75-2.1875 \cdot\left(\frac{a}{d}\right)+1.9375 \cdot\left(\varepsilon_{r}\right)-0.625 \cdot h r+3 \cdot t h-8.75 \cdot \theta+0.25 \cdot\left(\frac{a}{d}\right) \cdot\left(\varepsilon_{r}\right)+0.5 \cdot\left(\frac{a}{d}\right) \cdot h r \\
& -0.25 \cdot\left(\frac{a}{d}\right) \cdot \operatorname{th}-0.25 \cdot\left(\frac{a}{d}\right) \cdot \theta-0.25 \cdot\left(\varepsilon_{r}\right) \cdot h r-0.25 \cdot\left(\varepsilon_{r}\right) \cdot \theta-0.25 \cdot(h r) \cdot \theta+1.75 \cdot t h \cdot \theta \\
& -0.4792 \cdot\left(\frac{a}{d}\right)^{2}-0.3125\left(\varepsilon_{r}\right)^{2}-0.3958 \cdot(h r)^{2}+0.2708 \cdot(t h)^{2}+9.1042 \cdot(\theta)^{2}
\end{aligned}
$$

Figure 7 shows $\alpha_{i}$ magnitude of the 2-order equation (Equation (4)) for every input variable. In the statistical section, the significant terms of Equation (4) will be identified and their influence on the response value $(V B D)$. Equation (4) is applicable only for the electrode configuration point/plane gap and not for point/point or plane/plane gap.

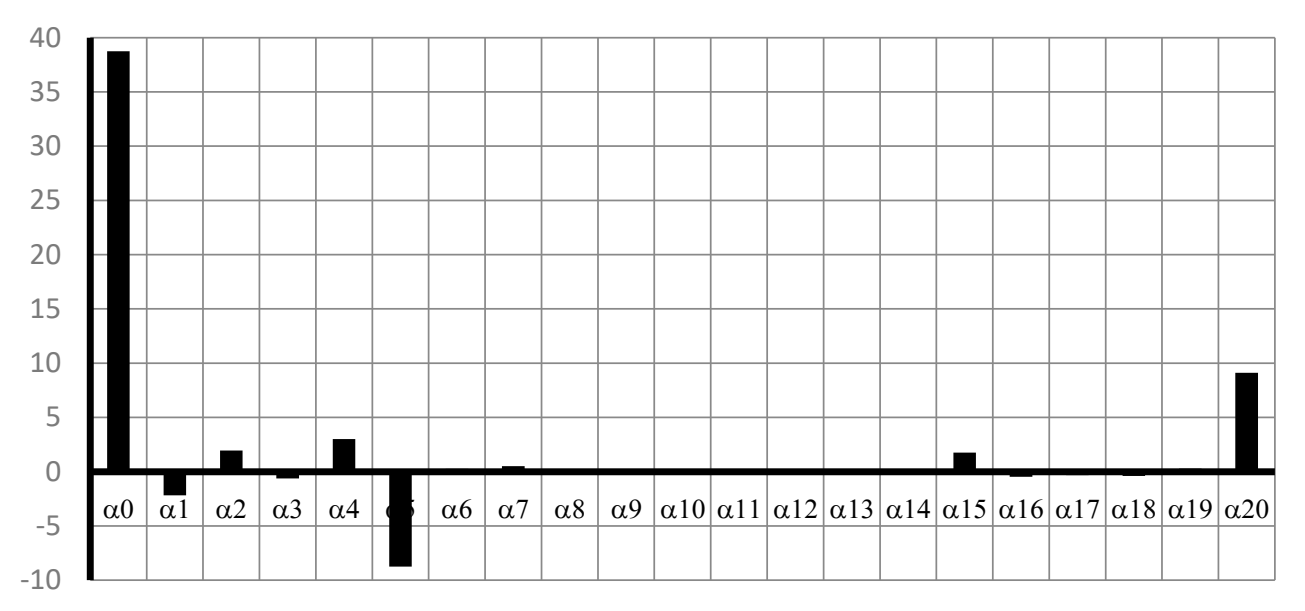

Figure 7. Value of $\alpha_{\mathrm{i}}$ of the BBD model for Equation (4).

\section{Statistical Analyses}

The approximate solution for Equation (4) can be developed using statistical analysis to explain the significant terms. The statistical analysis provides the regression analysis to evaluate the descriptive model quality [13]. The hypothesis test ( $p$-value) and critical value approach $\left(t_{\text {crit }}\right)$ can assess the significant terms in Equation (4). The $t$-test (tstat) is compared with $t_{c r i t}$ to determine the essential terms in the predicted equation. When tstat is greater than $t_{\text {crit }}$, this term is considered an effective term; otherwise, the term can be removed from the predicted equation. The $p$-value uses the possible probability to decide whether the null hypothesis is rejected by evaluating the $p$-value risk interval of $\beta=0.05$. The tstat can be assessed using $S E_{i}$ parameter. The $S E_{i}$ in Table 4 denotes the modification of residue coefficients that are computed by [13]:

$$
S E_{i}^{2}=\frac{\left(\frac{1}{N_{r}-N_{c}} \sum e_{i}^{2}\right)}{N_{r}}
$$

$N_{r}$ represents the experiment number, while $N_{c}$ denotes the number of used variable coefficients. Note that the variance between them, formulated by $N_{r}-N_{c}$, is named the number of degrees of freedom. In turn, $e_{i}$ denotes the residues that rapid the alteration between the measured and forecast values of the response $(V B D)$. 
Table 4. Statistical parameters and model coefficients using coded values (see Table 1).

\begin{tabular}{ccccc}
\hline & Coefficient & SE & Tstat & $p$-Value \\
\hline (Intercept $)$ & 38.75 & 0.33953 & 114.13 & $6.54 \times 10^{-17}$ \\
$(a / d) \%$ & -2.1875 & 0.20792 & -10.521 & $9.96 \times 10^{-7}$ \\
$\varepsilon_{r}$ & 1.9375 & 0.20792 & 9.3187 & $3.02 \times 10^{-6}$ \\
$h r$ & -0.625 & 0.20792 & -3.006 & 0.013207 \\
$t h$ & 3 & 0.20792 & 14.429 & $5.07 \times 10^{-8}$ \\
$\theta$ & -8.75 & 0.20792 & -42.084 & $1.38 \times 10^{-12}$ \\
$(a / d) \%: \varepsilon_{r}$ & 0.25 & 0.41583 & 0.6012 & 0.56108 \\
$(a / d) \%: h r$ & 0.5 & 0.41583 & 1.2024 & 0.2569 \\
$(a / d) \%: t h$ & -0.25 & 0.41583 & -0.6012 & 0.56108 \\
$(a / d) \%: \theta$ & -0.25 & 0.41583 & -0.6012 & 0.56108 \\
$\varepsilon_{r}: h r$ & -0.25 & 0.41583 & -0.6012 & 0.56108 \\
$\varepsilon_{r}: t h$ & $1.78 \times 10^{-15}$ & 0.41583 & $4.27 \times 10^{-15}$ & 1 \\
$\varepsilon_{r}: \theta$ & -0.25 & 0.41583 & -0.6012 & 0.56108 \\
$h r: t h$ & $5.32 \times 10^{-15}$ & 0.41583 & $1.28 \times 10^{-14}$ & 1 \\
$h r: \theta$ & -0.25 & 0.41583 & -0.6012 & 0.56108 \\
$t h: \theta$ & 1.75 & 0.41583 & 4.2084 & 0.001804 \\
$(a / d) \%{ }^{2}$ & -0.47917 & 0.28152 & -1.7021 & 0.11957 \\
$\varepsilon_{r}{ }^{2}$ & -0.3125 & 0.28152 & -1.11 & 0.29296 \\
$h r^{2}$ & -0.39583 & 0.28152 & -1.4061 & 0.19001 \\
$t h^{2}$ & 0.27083 & 0.28152 & 0.96204 & 0.35872 \\
$\theta^{2}$ & 9.1042 & 0.28152 & 32.339 & $1.88 \times 10^{-11}$ \\
\hline
\end{tabular}

The tstat represents the coefficient of $t$-test model. In Table 4 , tstat can be assessed by the ratio of the mathematical model's coefficients to the SE at each variable coefficient $\alpha_{i}$, as in Equation (6).

$$
\text { tstat }=\frac{\alpha_{i}}{S E_{i}}
$$

The $t$-test is used to examine the vital result of every input variable. The critical $t$-test value $\left(t_{\text {crit }}\right)$ can be calculated in Equation (7) as in [13].

$$
t_{\text {crit }}=\left(\beta, N_{r}-N_{c}\right)
$$

Based on the parameters of Equation (7), where the risk interval $\beta$ is equal to 0.05 and $N_{r}-N_{c}$ is equal to 25 , then $t_{c r i t}$ is equal to 1.708 . As shown in Table 3 , the tstat values corresponding to each $\alpha$ coefficient indicate that the most significant terms of Equation (4) on the VBD are the shaded rows in Table 3. The value of $p$-value sustains this fact, where every shaded row has a $p$-value less than 0.005 . The low $p$-value of each shaded row designates that the sample data can provide a productive indication to discard the null theory from the whole population of the experimental runs.

Note that the $p$-value (see Table 4 ) exemplifies which forecast variable significantly affects the response. Consequently, as for the $t$-test, the variables $(a / d) \%, \varepsilon_{r}, h r, t h, \theta$, $(t h \times \theta)$, and $\theta^{2}$ are significant terms of Equation (4) in the model, given that its $p$-value is less than 0.05 .

The other statistical parameters that assess the designed model's evocative excellence, such as the R-squared (R-sq), adjusted R-squared, and the F-statistic, can be determined in Table 5. As shown in Table 5, the R-squared is 0.993, which indicates the strong relation between the experiment variables and the experiment response. The adjusted R-squared is 0.983, which refers to the compatibility between the response's measured and predicted value. The F-statistic is 175 , which indicates the significant predictive capability of the designed model. The root means squared error of the developed model is very low (0.832), which means fewer differences between the measured and predicted response values. 
Table 5. Quality coefficients for model expressive.

\begin{tabular}{cc}
\hline Observation number & 46 \\
Freedom degree & 25 \\
Root mean squared error & 0.832 \\
R-squared & 0.993 \\
Attuned R-squared & 0.987 \\
F-statistic vs. constant model & 175 \\
$p$-value & $4.88 \times 10^{-22}$ \\
\hline
\end{tabular}

Figure 8 illustrates the variation in the experiment variables with the variation in the experiment response. As observed, the barrier thickness and the barrier's inclined angle are essential variables that influence the magnitude of the experiment response $(V B D)$. The absolute variation percentage of the $V B D$ to the barrier thickness variation is $((36.0208-42.0208) / 42.0208) \times 100=14.27 \%$, while the absolute deviation of the $V B D$ according to the inclined angle of the barrier is $((56.6042-39.1042) / 56.6042) \times 100)=30.9 \%$.

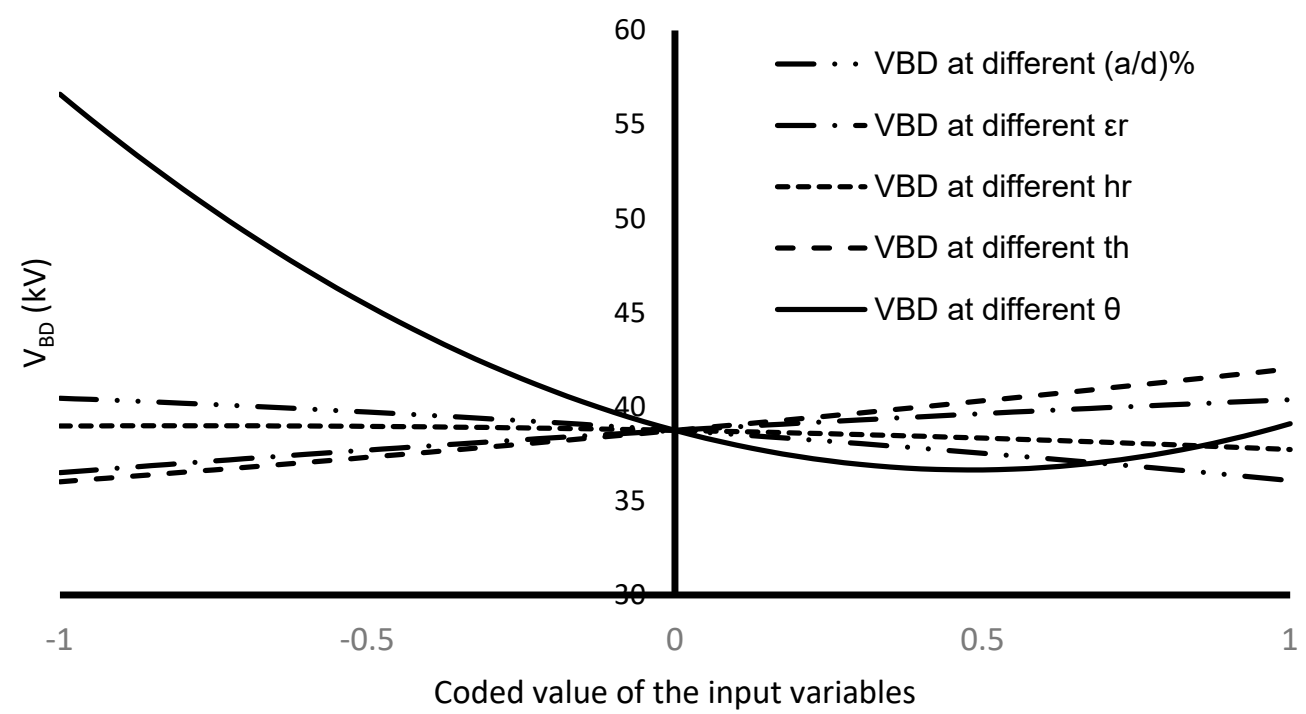

Figure 8. Impact of the adopted variables on $V B D$.

Equation (4) can be approximated to Equation (8) by eliminating the variables that insignificantly affect the response, according to Table 4 . The approximation equation is explained as follows:

$V B D=38.75-2.1875 \cdot\left(\frac{a}{d}\right)+1.9375 \cdot\left(\varepsilon_{r}\right)-0.625 \cdot h r+3 \cdot t h-8.75 \cdot \theta+1.75 \cdot t h \cdot \theta+9.1042 \cdot(\theta)^{2}$

Table 6 illustrates the residual percentage between the measured value of $V B D$ and the predicted value from Equations (4) and (8). The residual percentage refers to the percentage difference between the measured $V B D$ (actual) and the predicted $V B D$ using the BBD technique (simulation) at certain experiment conditions as in Tables 6 and 7. As shown in Table 6, the maximum residual percentage from Equation (4) is 3.81\% at the run number of 18 , and the maximum residual percentage from Equation (8) is 5.19\% at the run number of 36. All other residual percentages are within acceptable limits. 
Table 6. Residual \% between the measured $V B D$ and predicted $V B D$ based on Equations (4) and (8).

\begin{tabular}{|c|c|c|c|c|c|c|c|}
\hline & \multirow{2}{*}{$\begin{array}{c}\text { Measured } \\
V B D\end{array}$} & \multicolumn{3}{|c|}{ Equation (4) } & \multicolumn{3}{|c|}{ Equation (8) } \\
\hline & & Predicted $V B D$ & Residual & Residual \% & Predicted $V B D$ & Residual & Residual \% \\
\hline 1 & 38 & 38.4583 & 0.4583 & 1.206053 & 39 & 1 & 2.564103 \\
\hline 2 & 42 & 41.8333 & 0.1667 & 0.396905 & 42.875 & 0.875 & 2.040816 \\
\hline 3 & 33 & 33.5833 & 0.5833 & 1.767576 & 34.625 & 1.625 & 4.693141 \\
\hline 4 & 38 & 37.9583 & 0.0417 & 0.109737 & 38.5 & 0.5 & 1.298701 \\
\hline 5 & 36 & 36.25 & 0.25 & 0.694444 & 36.375 & 0.375 & 1.030928 \\
\hline 6 & 43 & 42.25 & 0.75 & 1.744186 & 42.375 & 0.625 & 1.474926 \\
\hline 7 & 34 & 35 & 1 & 2.941176 & 35.125 & 1.125 & 3.202847 \\
\hline 8 & 41 & 41 & 0 & 0 & 41.125 & 0.125 & 0.303951 \\
\hline 9 & 54 & 54.3542 & 0.3542 & 0.655926 & 54.6667 & 0.6667 & 1.219572 \\
\hline 10 & 38 & 36.8542 & 1.1458 & 3.015263 & 37.1667 & 0.8333 & 2.242061 \\
\hline 11 & 58 & 58.2292 & 0.2292 & 0.395172 & 58.5417 & 0.5417 & 0.925323 \\
\hline 12 & 41 & 40.7292 & 0.2708 & 0.660488 & 41.0417 & 0.0417 & 0.101604 \\
\hline 13 & 41 & 41.1875 & 0.1875 & 0.457317 & 41.5625 & 0.5625 & 1.353383 \\
\hline 14 & 39 & 38.9375 & 0.0625 & 0.160256 & 40.3125 & 1.3125 & 3.255814 \\
\hline 15 & 36 & 35.8125 & 0.1875 & 0.520833 & 37.1875 & 1.1875 & 3.193277 \\
\hline 16 & 36 & 35.5625 & 0.4375 & 1.215278 & 35.9375 & 0.0625 & 0.173913 \\
\hline 17 & 57 & 55.625 & 1.375 & 2.412281 & 55.3542 & 1.6458 & 2.973216 \\
\hline 18 & 36 & 34.625 & 1.375 & 3.819444 & 34.3542 & 1.6458 & 4.790681 \\
\hline 19 & 57 & 58.125 & 1.125 & 1.973684 & 57.8542 & 0.8542 & 1.47647 \\
\hline 20 & 43 & 44.125 & 1.125 & 2.616279 & 43.8542 & 0.8542 & 1.947818 \\
\hline 21 & 37 & 36.4792 & 0.5208 & 1.407568 & 37.4375 & 0.4375 & 1.168614 \\
\hline 22 & 36 & 35.7292 & 0.2708 & 0.752222 & 36.1875 & 0.1875 & 0.518135 \\
\hline 23 & 41 & 40.8542 & 0.1458 & 0.35561 & 41.3125 & 0.3125 & 0.75643 \\
\hline 24 & 39 & 39.1042 & 0.1042 & 0.267179 & 40.0625 & 1.0625 & 2.652106 \\
\hline 25 & 37 & 37.4791 & 0.4791 & 1.294865 & 37.9375 & 0.9375 & 2.47117 \\
\hline 26 & 44 & 43.9791 & 0.0209 & 0.0475 & 43.9375 & 0.0625 & 0.142248 \\
\hline 27 & 34 & 33.6041 & 0.3959 & 1.164412 & 33.5625 & 0.4375 & 1.303538 \\
\hline 28 & 40 & 39.1041 & 0.8959 & 2.23975 & 39.5625 & 0.4375 & 1.105845 \\
\hline 29 & 56 & 56.5834 & 0.5834 & 1.041786 & 57.2292 & 1.2292 & 2.147855 \\
\hline 30 & 39 & 39.5834 & 0.5834 & 1.495897 & 39.7292 & 0.7292 & 1.835426 \\
\hline 31 & 56 & 55.8334 & 0.1666 & 0.2975 & 55.9792 & 0.0208 & 0.037157 \\
\hline 32 & 38 & 37.8334 & 0.1666 & 0.438421 & 38.4792 & 0.4792 & 1.245348 \\
\hline 33 & 59 & 58.0625 & 0.9375 & 1.588983 & 58.7917 & 0.2083 & 0.354302 \\
\hline 34 & 41 & 41.0625 & 0.0625 & 0.152439 & 41.2917 & 0.2917 & 0.706437 \\
\hline 35 & 54 & 54.1875 & 0.1875 & 0.347222 & 54.4167 & 0.4167 & 0.765758 \\
\hline 36 & 35 & 36.1875 & 1.1875 & 3.392857 & 36.9167 & 1.9167 & 5.191959 \\
\hline 37 & 33 & 33.7708 & 0.7708 & 2.335758 & 33.8125 & 0.8125 & 2.402957 \\
\hline 38 & 40 & 39.7708 & 0.2292 & 0.573 & 39.8125 & 0.1875 & 0.470958 \\
\hline 39 & 37 & 37.6458 & 0.6458 & 1.745405 & 37.6875 & 0.6875 & 1.824212 \\
\hline 40 & 44 & 43.6458 & 0.3542 & 0.805 & 43.6875 & 0.3125 & 0.715308 \\
\hline 41 & 39 & 38.75 & 0.25 & 0.641026 & 38.75 & 0.25 & 0.645161 \\
\hline 42 & 38.5 & 38.75 & 0.25 & 0.649351 & 38.75 & 0.25 & 0.645161 \\
\hline 43 & 38 & 38.75 & 0.75 & 1.973684 & 38.75 & 0.75 & 1.935484 \\
\hline 44 & 38.5 & 38.75 & 0.25 & 0.649351 & 38.75 & 0.25 & 0.645161 \\
\hline 45 & 39 & 38.75 & 0.25 & 0.641026 & 38.75 & 0.25 & 0.645161 \\
\hline 46 & 39.5 & 38.75 & 0.75 & 1.898734 & 38.75 & 0.75 & 1.935484 \\
\hline
\end{tabular}


Table 7. Residuals \% of Equations (4) and (8) according to the measured VBD for additional random experiments.

\begin{tabular}{|c|c|c|c|c|c|c|c|c|c|c|c|c|}
\hline & \multirow{2}{*}{$(a / d) \%$} & \multirow{2}{*}{$\varepsilon_{r}$} & \multirow{2}{*}{$h r$} & \multirow{2}{*}{ th } & \multirow{2}{*}{$\theta$} & \multirow{2}{*}{$\begin{array}{c}\text { Measured } \\
\text { VBDD }\end{array}$} & \multicolumn{3}{|c|}{ Predicted VBD from Equation (4) } & \multicolumn{3}{|c|}{ Predicted $V B D$ from Equation (8) } \\
\hline & & & & & & & $V B D$ & Residual & Residual \% & $V B D$ & Residual & Residual \% \\
\hline 1 & 0 & 1 & 1 & 1 & 0 & 44 & 42.375 & 1.625 & 3.693182 & 43.0625 & 0.9375 & 2.177068 \\
\hline 2 & 0 & 1 & -1 & 1 & 0 & 46 & 44.125 & 1.875 & 4.076087 & 44.3125 & 1.6875 & 3.808181 \\
\hline 3 & 0 & 1 & 1 & -1 & 0 & 37 & 36.375 & 0.625 & 1.689189 & 37.0625 & 0.0625 & 0.168634 \\
\hline 4 & 0 & -1 & 1 & 1 & 0 & 38 & 39 & 1 & 2.631579 & 39.1875 & 1.1875 & 3.030303 \\
\hline 5 & 1 & 0 & 1 & 0 & 1 & 35 & 35.4167 & 0.4167 & 1.190571 & 36.2917 & 1.2917 & 3.559216 \\
\hline 6 & 1 & 0 & -1 & 0 & -1 & 53 & 53.6667 & 0.6667 & 1.257925 & 55.0417 & 2.0417 & 3.709369 \\
\hline 7 & 1 & 0 & -1 & 0 & 1 & 36 & 36.1667 & 0.1667 & 0.463056 & 37.5417 & 1.5417 & 4.106633 \\
\hline 8 & -1 & 1 & 1 & 1 & 0 & 45 & 43.5833 & 1.4167 & 3.148222 & 45.25 & 0.25 & 0.552486 \\
\hline 9 & -1 & 1 & -1 & 1 & 0 & 47 & 46.3333 & 0.6667 & 1.418511 & 46.5 & 0.5 & 1.075269 \\
\hline 10 & -1 & 1 & -1 & -1 & 0 & 40 & 39.8333 & 0.1667 & 0.41675 & 40.5 & 0.5 & 1.234568 \\
\hline 11 & -1 & 0 & 0 & 1 & -1 & 59 & 59.8333 & 0.8333 & 1.412373 & 60.0417 & 1.0417 & 1.734961 \\
\hline 12 & -1 & 0 & 0 & -1 & -1 & 59 & 56.8333 & 2.1667 & 3.672373 & 57.5417 & 1.4583 & 2.534336 \\
\hline 13 & 0 & 0 & 1 & 1 & 1 & 43 & 42.8542 & 0.1458 & 0.33907 & 43.2292 & 0.2292 & 0.530197 \\
\hline 14 & 0 & 0 & 1 & 1 & -1 & 57 & 57.3542 & 0.3542 & 0.621404 & 57.2292 & 0.2292 & 0.400495 \\
\hline 15 & 0 & 0 & 1 & -1 & 1 & 32 & 33.3542 & 1.3542 & 4.231875 & 33.7292 & 1.7292 & 5.126715 \\
\hline 16 & 0 & 0 & 1 & -1 & -1 & 57 & 54.8542 & 2.1458 & 3.764561 & 54.7292 & 2.2708 & 4.149156 \\
\hline 17 & 1 & -1 & -1 & -1 & -1 & 52 & 50.1875 & 1.8125 & 3.485577 & 51.8542 & 0.1458 & 0.281173 \\
\hline 18 & 0 & 1 & 0 & 1 & -1 & 58 & 59.75 & 1.75 & 3.017241 & 59.7917 & 1.7917 & 2.99657 \\
\hline 19 & 1 & 1 & -1 & -1 & -1 & 54 & 55.0625 & 1.0625 & 1.967593 & 55.7292 & 1.7292 & 3.102862 \\
\hline 20 & 1 & 1 & -1 & 1 & 1 & 44 & 43.0625 & 0.9375 & 2.130682 & 44.2292 & 0.2292 & 0.51821 \\
\hline
\end{tabular}

\section{Validation of the Predictive Mathematical Model}

Some other random experimental works are accomplished to evaluate the robustness of the predictive model. Table 7 explains 20 random experiment results with the measured $V B D$ and the predicted $V B D$ based on Equations (4) and (8). The obtained results demonstrate that the designed BBD model can predict the $V B D$ based on Equations (4) and (8). As shown in Table 7, the maximum residual percentage is 5.12\% at the run number 15 . All other residual results are in the acceptable range $(<5 \%)$.

\section{Conclusions}

New barrier variables were presented to investigate their consequence on the insulating oil VBD. These new variables are barrier location $(a / d) \%$, dielectric constant $\left(\varepsilon_{r}\right)$ of the barrier material, barrier hole radius $(h r)$, barrier thickness $(t h)$, and the barrier inclined angle $(\theta)$. The experimental work results indicated that two parameters significantly affect the $V B D$ of the insulating oil: the first one is the thickness of the barrier (th), and the second is the barrier inclined angle $(\theta)$. BBD design was used to develop a predicted model to identify the $V B D$ with the barrier variables' variation. The designed DDB model is constructed for the five barrier variables with 46 experiment runs with specified forms. The BBD model results generate low residual errors between the measured $V B D$ and predicted $V B D$ based on Equations (4) and (8). The residual percentage of the predicted $V B D$ from Equation (4) is less than $5 \%$ for all 46 experiment runs.

The mathematical model is constructed based on the coded values $(-1,0,1)$, where -1 refers to the minimum value of the variable $x, 0$ refers to the mean of the variable $x$, and 1 refers to the maximum value of $x$. Therefore, the constructed model can be validated using the input parameters' coded values $(-1,0,1)$.

New 30 random experiment cases were used to measure the robustness and quality of the designed model to validate the BBD model with other experiment cases. All the residual percentages of all cases for Equation (4) are less than 5\%. The approximation predicted $V B D$ equation is developed on the basis of the statistical analysis using $t$-test and $p$-value. Then, the approximated Equation (8) is developed. The results show that only one case in the 46 experiment runs generates a residual percentage of $5.19 \%$, and the other 20 validation experiment runs also generate one case with a residual percentage of $5.12 \%$. 
Consequently, Equations (4) and (8) can predict the $V B D$ of the insulating oil for any other new cases.

In future work, the application of nanotechnology for enhancing the breakdown voltage strength of various insulating materials [44-52] in the presence of different barrier effects will be investigated, specifically in the transformer insulating oil.

Author Contributions: All authors have contributed to the preparation of this manuscript. S.S.M.G., A.B.A.S. and A.A.E. designed the idea strategy, studied the data, conduct the experiments, and wrote the manuscript. M.M.F.D. and K.M. revised and proofread the manuscript. Finally, S.S.D., A.B. and M.L. reviewed, edited, funded, and supported different improvements for the manuscript. All authors have read and agreed to the published version of the manuscript.

Funding: This research was funded by Taif University Researchers Supporting Project Number (TURSP-2020/34), Taif University, Taif, Saudi Arabia, and the Department of Electrical Engineering and Automation, School of Electrical Engineering, Aalto University, Espoo, Finland.

Institutional Review Board Statement: Not applicable.

Informed Consent Statement: Not applicable.

Data Availability Statement: The data presented in this study are available on request from the corresponding author.

Acknowledgments: The authors would like to acknowledge the financial support received from Taif University Researchers Supporting Project Number (TURSP-2020/34), Taif University, Taif, Saudi Arabia. The authors also thank the Extra High-Voltage Research Center of the Egyptian Electricity Holding Company, Egypt, for support on the experimental works as well as the Department of Electrical Engineering and Automation, School of Electrical Engineering, Aalto University, Espoo, Finland. Finally, the authors dedicate this research to the memory of the coauthor Sobhy S. Dessouky who passed suddenly away on 18 March 2021, during the revision process of this paper.

Conflicts of Interest: The authors declare no conflict of interest.

\section{References}

1. Ghoneim, S.S.M.; Taha, I.B.M.; Elkalashy, N.I. Integrated ANN-Based Proactive Fault Diagnostic Scheme for Power Transformers Using Dissolved Gas Analysis. IEEE Trans. Dielectr. Electr. Insul. 2016, 23, 1838-1845. [CrossRef]

2. Ghoneim, S.S.M.; Mahmoud, K.; Lehtonen, M.; Darwish, M.M.F. Enhancing Diagnostic Accuracy of Transformer Faults Using Teaching-Learning Based Optimization. IEEE Access 2021, 9, 30817-30832. [CrossRef]

3. Guerbas, F.; Zitouni, M.; Boubakeur, A.; Beroual, A. Barrier effect on breakdown of point-plane oil gaps under alternating current voltage. IET Gener. Transm. Distrib. 2010, 4, 1245-1250. [CrossRef]

4. Alshehawy, A.M.; Mansour, D.M.; Ghali, M.; Lehtonen, M.; Darwish, M.M.F. Photoluminescence Spectroscopy Measurements for Effective Condition Assessment of Transformer Insulating Oil. Processes 2021, 9. under review.

5. Ward, S.A.; El-Faraskoury, A.; Badawi, M.; Ibrahim, S.A.; Mahmoud, K.; Lehtonen, M.; Darwish, M.M.F. Towards Precise Interpretation of Oil Transformers via Novel Combined Techniques Based on DGA and Partial Discharge Sensors. Sensors 2021, 21, 2223. [CrossRef]

6. Ghoneim, S.S.M. Determination of Transformers' Insulating Paper State Based on Classification Techniques. Processes 2021, 9, 427. [CrossRef]

7. Abouelatta, M.A.; Ward, S.A.; Sayed, A.M.; Mahmoud, K.; Lehtonen, M.; Darwish, M.M.F. Fast Corona Discharge Assessment Using FDM integrated with Full Multigrid Method in HVDC Transmission Lines Considering Wind Impact. IEEE Access 2020, 8, 225872-225883. [CrossRef]

8. Mansour, D.-E.A.; Abdel-Gawad, N.M.K.; El Dein, A.Z.; Ahmed, H.M.; Darwish, M.M.F.; Lehtonen, M. Recent Advances in Polymer Nanocomposites Based on Polyethylene and Polyvinylchloride for Power Cables. Materials 2021, 14, 66. [CrossRef]

9. Dessouky, S.; Ghoneim, S.; Elfaraskoury, A.; Abosharaf, A.B. Barrier Effect on the Dielectric Strength of the Transformer Insulating Oils. In Proceedings of the 20th International Symposium on High Voltage Engineering, Buenos Aires, Argentina, 27 August-1 September 2017.

10. Mohd, A.; Khan, W. Breakdown Characteristics of Ambient Medium in Presence of Barrier under Varying Field Conditions. Int. J. Adv. Res. Electr. Electron. Instrum. Eng. 2016, 5, 6.

11. Beroual, A.; Boubakeur, A. Influence of barriers on the lightning and impulse strength of mean air gaps in point/plane arrangements. IEEE Trans. Electr. Insul. 1991, 26, 1130-1139. [CrossRef]

12. Guerbas, F. Influence des Barrières sur la Rigidité Diélectrique de L’huile Minérale'. Ph.D. Thesis, Department of Electrical Engineering, Ecole National Polytechnique, Algiers, Algeria, June 2011. 
13. Zitouni, M.; Guerbas, F.; Boukezzi, L.; Boubakeur, A. Modelling by design of experiments method of the AC breakdown voltage of transformer oil point-plane gaps with insulating barrier. IET Gener. Transm. Distrib. 2016, 10, 232-239. [CrossRef]

14. Schueller, M.; Blaszczyk, A.; Krivda, A.; Smajic, J. Influence of the surface conductivity of a single glass barrier on the breakdown voltage in an air insulated rod plane arrangement. In Proceedings of the 2016 IEEE Conference on Electrical Insulation and Dielectric Phenomena (CEIDP), Toronto, ON, Canada, 16-19 October 2016.

15. Studniarz, S.A. The Effect of Barriers in the Low Field Regions of Non-Uniform Fields on Oil Breakdown. IEEE Trans. Power Appar. Syst. 1981, 4, 1568-1573. [CrossRef]

16. Mahmud, S.; Golosnoy, I.O.; Chen, G.; Wilson, G.; Jarman, P. Effect of Kraft Paper Barriers on Bridging in Contaminated Transformer Oil. In Proceedings of the 2014 IEEE Conference on Electrical Insulation and Dielectric Phenomena (CEIDP), Des Moines, IA, USA, 19-22 October 2014; pp. 110-113.

17. Ali, M.N.; Mahmoud, K.; Lehtonen, M.; Darwish, M.M.F. An Efficient Fuzzy-Logic Based Variable-Step Incremental Conductance MPPT Method for Grid-Connected PV Systems. IEEE Access 2021, 9, 26420-26430. [CrossRef]

18. Ali, M.N.; Mahmoud, K.; Lehtonen, M.; Darwish, M.M.F. Promising MPPT Methods Combining Metaheuristic, Fuzzy-Logic and ANN Techniques for Grid-Connected Photovoltaic. Sensors 2021, 21, 1244. [CrossRef]

19. Ali, E.S.; El-Sehiemy, R.A.; Abou El-Ela, A.A.; Mahmoud, K.; Lehtonen, M.; Darwish, M.M.F. An Effective Bi-Stage Method for Renewable Energy Sources Integration into Unbalanced Distribution Systems Considering Uncertainty. Processes $2021,9,471$. [CrossRef]

20. Bayoumi, A.S.; El-Sehiemy, R.A.; Mahmoud, K.; Lehtonen, M.; Darwish, M.M.F. Assessment of an Improved Three-Diode against Modified Two-Diode Patterns of MCS Solar Cells Associated with Soft Parameter Estimation Paradigms. Appl. Sci. 2021, 11, 1055. [CrossRef]

21. Abbas, A.S.; El-Sehiemy, R.A.; Abou El-Ela, A.; Ali, E.S.; Mahmoud, K.; Lehtonen, M.; Darwish, M.M.F. Optimal Harmonic Mitigation in Distribution Systems with Inverter Based Distributed Generation. Appl. Sci. 2021, 11, 774. [CrossRef]

22. Elsisi, M.; Mahmoud, K.; Lehtonen, M.; Darwish, M.M.F. An Improved Neural Network Algorithm to Efficiently Track Various Trajectories of Robot Manipulator Arms. IEEE Access 2021, 9, 11911-11920. [CrossRef]

23. Elsisi, M.; Tran, M.-Q.; Mahmoud, K.; Lehtonen, M.; Darwish, M.M.F. Deep Learning-Based Industry 4.0 and Internet of Things towards Effective Energy Management for Smart Buildings. Sensors 2021, 21, 1038. [CrossRef] [PubMed]

24. Elsisi, M.; Mahmoud, K.; Lehtonen, M.; Darwish, M.M.F. Reliable Industry 4.0 Based on Machine Learning and IoT for Analyzing, Monitoring, and Securing Smart Meters. Sensors 2021, 21, 487.

25. Abaza, A.; El-Sehiemy, R.A.; Mahmoud, K.; Lehtonen, M.; Darwish, M.M.F. Optimal Estimation of Proton Exchange Membrane Fuel Cells Parameter Based on Coyote Optimization Algorithm. Appl. Sci. 2021, 11, 252. [CrossRef]

26. Said, M.; Shaheen, A.M.; Ginidi, A.R.; El-Sehiemy, R.A.; Mahmoud, K.; Lehtonen, M.; Darwish, M.M.F. Estimating Parameters of Photovoltaic Models Using Accurate Turbulent Flow of Water Optimizer. Processes 2021, 9, 627. [CrossRef]

27. Bendary, A.F.; Abdelaziz, A.Y.; Ismail, M.M.; Mahmoud, K.; Lehtonen, M.; Darwish, M.M.F. Proposed ANFIS Based Approach for Fault Tracking, Detection, Clearing and Rearrangement for Photovoltaic System. Sensors 2021, 21, 2269. [CrossRef]

28. Elsisi, M.; Tran, M.Q.; Mahmoud, K.; Lehtonen, M.; Darwish, M.M. Robust Design of ANFIS-Based Blade Pitch Controller for Wind Energy Conversion Systems Against Wind Speed Fluctuations. IEEE Access 2021, 9, 37894-37904. [CrossRef]

29. Ghoneim, S.S.; Dessouky, S.S.; Elfaraskoury, A.A.; Sharaf, A.B.A. Prediction of insulating transformer oils breakdown voltage considering barrier effect based on artificial neural networks. Electr. Eng. 2018, 100, 2231-2242. [CrossRef]

30. Krishna, D.; Krishna, K.S.; Sree, R.P. Response Surface Modeling and Optimization of Chromium (Vi) Removal from Aqueous Solution Using Borasus Flabellifer Coir Powder. Int. J. Appl. Sci. Eng. 2013, 11, 213-226.

31. Ghoneim, S.S.; Dessouky, S.S.; Elfaraskoury, A.A.; Abou Sharaf, A.B. Modelling and Experimental Verification of Barrier Effect on Breakdown Voltage of Transformer Oil Using Box-Behnken Design. Measurement 2019, 147, 2-9. [CrossRef]

32. IEC 60156. Insulating Liquids-Determination of the Breakdown Voltage at Power Frequency-Test Method. Available online: https: / / webstore.iec.ch/publication/ 63770 (accessed on 1 March 2021).

33. IEC 60296. Fluids for Electrotechnical Applications-Mineral Insulating Oils for Electrical Equipment. Available online: https:/ / webstore.iec.ch/publication/61025 (accessed on 1 March 2021).

34. Cavazzuti, M. Optimization Methods: From Theory to Design; Springer: Berlin/Heidelberg, Germany, 2013 ; p. 25.

35. Demirçivi, P.; Saygıll, G.N. Response surface modeling of boron adsorption from aqueous solution by vermiculite using different adsorption agents: Box-Behnken experimental design. Water Sci. Technol. 2017, 76, 515-530. [CrossRef]

36. Fukuda, I.M.; Pinto, C.F.F.; Moreira, C.D.S.; Saviano, A.M.; Lourenço, F.R. Design of Experiments (DoE) applied to Pharmaceutical and Analytical Quality by Design (QbD). Braz. J. Pharm. Sci. 2018, 54, 1-16. [CrossRef]

37. Tayeb, A.M.; Tony, M.A.; Mansour, S.A. Application of Box-Behnken factorial design for parameters optimization of basic dye removal using nano-hematite photo-Fentontool. Appl. Water Sci. 2018, 8, 1-9. [CrossRef]

38. Hsu, Y.-T.; Su, C.-S. Application of Box-Behnken Design to Investigate the Effect of Process Parameters on the Microparticle Production of Ethenzamide through the Rapid Expansion of the Supercritical Solutions Process. Pharmaceutics 2020, 12, 42. [CrossRef]

39. Zaky, R.R.; Hessien, M.M.; El-Midany, A.A.; Khedr, M.H.; Abdel-Aal, E.A.; El-Barawy, K.A. Preparation of silica nanoparticles from semi-burned rice straw ash. Powder Technol. 2008, 185, 31-35. [CrossRef] 
40. Shu, G.; Dai, C.; Chen, H.; Wang, X. (Application of Box-Behnken design in optimization for crude polysaccharides from fruits of Tribulus terristris L. J. Chem. Pharm. Res. 2013, 5, 342-350.

41. Montgomerry, D.C. Design and Analysis of Experiments, 5th ed.; John Wiley Sons: New York, NY, USA, 2001.

42. Ferreira, S.C.; Bruns, R.E.; Ferreira, H.S.; Matos, G.D.; David, J.M.; Brandão, G.C.; Silva, E.G.P.; Portugal, L.A.; Dos Reis, P.S.; Souza, A.S.; et al. Box-Behnken design: An alternative for the optimization of analytical methods. Anal. Chim. Acta 2007, 597, 179-186. [CrossRef]

43. George, P.M. Machinability Analysis of Carbon Carbon Composites Using EDM. Ph.D. Thesis, Production Engineering, Sardar Patel University, Gujarat, India, December 2004.

44. Abdel-Gawad, N.M.; El Dein, A.Z.; Mansour, D.A.; Ahmed, H.M.; Darwish, M.M.; Lehtonen, M. Development of industrial scale PVC nanocomposites with comprehensive enhancement in dielectric properties. IET Sci. Meas. Technol. 2019, 13, 90-96. [CrossRef]

45. Abdel-Gawad, N.M.; El Dein, A.Z.; Mansour, D.A.; Ahmed, H.M.; Darwish, M.M.F. Effect of functionalized TiO 2 nanoparticles on dielectric properties of PVC nanocomposites used in electrical insulating cables. In Proceedings of the IEEE Eighteenth International Middle East Power Systems Conference (MEPCON), Cairo, Egypt, 27-29 December 2016; pp. 693-698. [CrossRef]

46. Abdel-Gawad, N.M.; El Dein, A.Z.; Mansour, D.A.; Ahmed, H.M.; Darwish, M.M.F.; Lehtonen, M. PVC nanocomposites for cable insulation with enhanced dielectric properties, partial discharge resistance and mechanical performance. High Volt. 2020, 5, 463-471. [CrossRef]

47. Abdel-Gawad, N.M.K.; Shaalan, E.M.; Darwish, M.M.F.; Basuny, M.A.M. Influence of Fault Locations on the Pipeline Induced Voltages Near to Power Transmission Lines. In Proceedings of the IEEE 21st International Middle East Power Systems Conference (MEPCON), Cairo, Egypt, 17-19 December 2019; pp. 761-767. [CrossRef]

48. Karaman, H.S.; Ahmed, H.M.; Darwish, M.M.F.; Mansour, D.A. The Effect of Geraphene on the Thermal and Dielectric Properties of Epoxy Resin. In Proceedings of the IEEE International Symposium on Electrical Insulating Materials (ISEIM), Tokyo, Japan, 13-17 September 2020; pp. 103-106.

49. Abdel-Gawad, N.M.K.; El-Kady, E.Y.; El Dein, A.Z.; Mansour, D.A.; Ahmed, H.M.; Darwish, M.M.F. Dielectric Response of PVC and LDPE Nanocomposites Upon Functionalization of Their Containing Nanoparticles. In Proceedings of the IEEE Twentieth International Middle East Power Systems Conference (MEPCON), Cairo, Egypt, 18-20 December 2018; pp. 1081-1086. [CrossRef]

50. Darwish, M.M.F.; Ahmed, H.M.; Mansour, D.A. Thermo-Mechanical Properties of LDPE/SiO2 Nanocomposites based on Chemically Functionalized SiO2 Nanoparticles. In Proceedings of the IEEE International Symposium on Electrical Insulating Materials (ISEIM), Tokyo, Japan, 13-17 September 2020; pp. 241-244.

51. Abdel-Gawad, N.M.; El Dein, A.Z.; Mansour, D.A.; Ahmed, H.M.; Darwish, M.M.F.; Lehtonen, M. Impact of Nanoparticles Functionalization on Partial Discharge Activity within PVC/SiO2 Nanocomposites. In Proceedings of the IEEE 2nd International Conference on Dielectrics (ICD), Budapest, Hungary, 1-5 July 2018; pp. 1-4. [CrossRef]

52. Abdel-Gawad, N.M.; El Dein, A.Z.; Mansour, D.A.; Ahmed, H.M.; Darwish, M.M.F.; Lehtonen, M. Experimental measurements of partial discharge activity within LDPE/TiO2 nanocomposites. In Proceedings of the IEEE Nineteenth International Middle East Power Systems Conference (MEPCON), Cairo, Egypt, 19-21 December 2017; pp. 811-816. [CrossRef] 